\title{
Diversity health checks in undergraduate curricula
}

\author{
Hope Chow ${ }^{1}$, Amali U Lokugamage ${ }^{1,2}$ and Faye Gishen ${ }^{1,3}$
}

${ }^{1}$ University College London Medical School, London, UK ${ }^{2}$ Whittington Health NHS Trust, London, UK ${ }^{3}$ Royal Free NHS Foundation Trust, London, UK

An equality and diversity syllabus is essential for a modern undergraduate health care professional curriculum, so that future health care professionals can best serve diverse populations. Diversity-related teaching can inculcate cultural competence and reduce prejudice in clinicians. The UK's General Medical Council also reinforces the importance of understanding 'the potential impact of [doc- tors'] attitudes, values, beliefs, perceptions and personal biases (which may be unconscious) on individuals and groups and identify personal strategies to address this'.1

The University College London (UCL) Black and Minority Ethnicity Attainment Project is a cross-disciplinary project team aiming to narrow the attainment gap using faculty-specific data. They recently proposed 'inclusivity health checks', with a checklist to evaluate how well undergraduate curricula cover equality, diversity, inclusion and human rights. ${ }^{2}$ As academics and students interested in diversity, we discovered the paucity of published materials on diversity curricula and decided to apply the principles of the 'inclusivity health check' to the University College London Medical School (UCLMS) context by mapping the UCLMS diversity curriculum. This also functioned as a gap analysis, allowing us to identify any key omissions. The UCLMS is a large UK-based medical school with a 6-year Bachelor of Medicine, Bachelor of Surgery (MBBS) medical course, where diversity-related teaching is primarily delivered via Clinical and Professional Practice (CPP) modules, spirally building through the 6-year syllabus3. Each CPP teaching session was scored according to the level of coverage of 12 different diversity-related themes, agreed by consensus, by UCL student and staff stakeholders with an interest in inclusive curricula (Figure 1). Academic leads also suggested relevant scholarly and extracurricular activities, such as UCL student support talks, to reflect institutional engagement. 


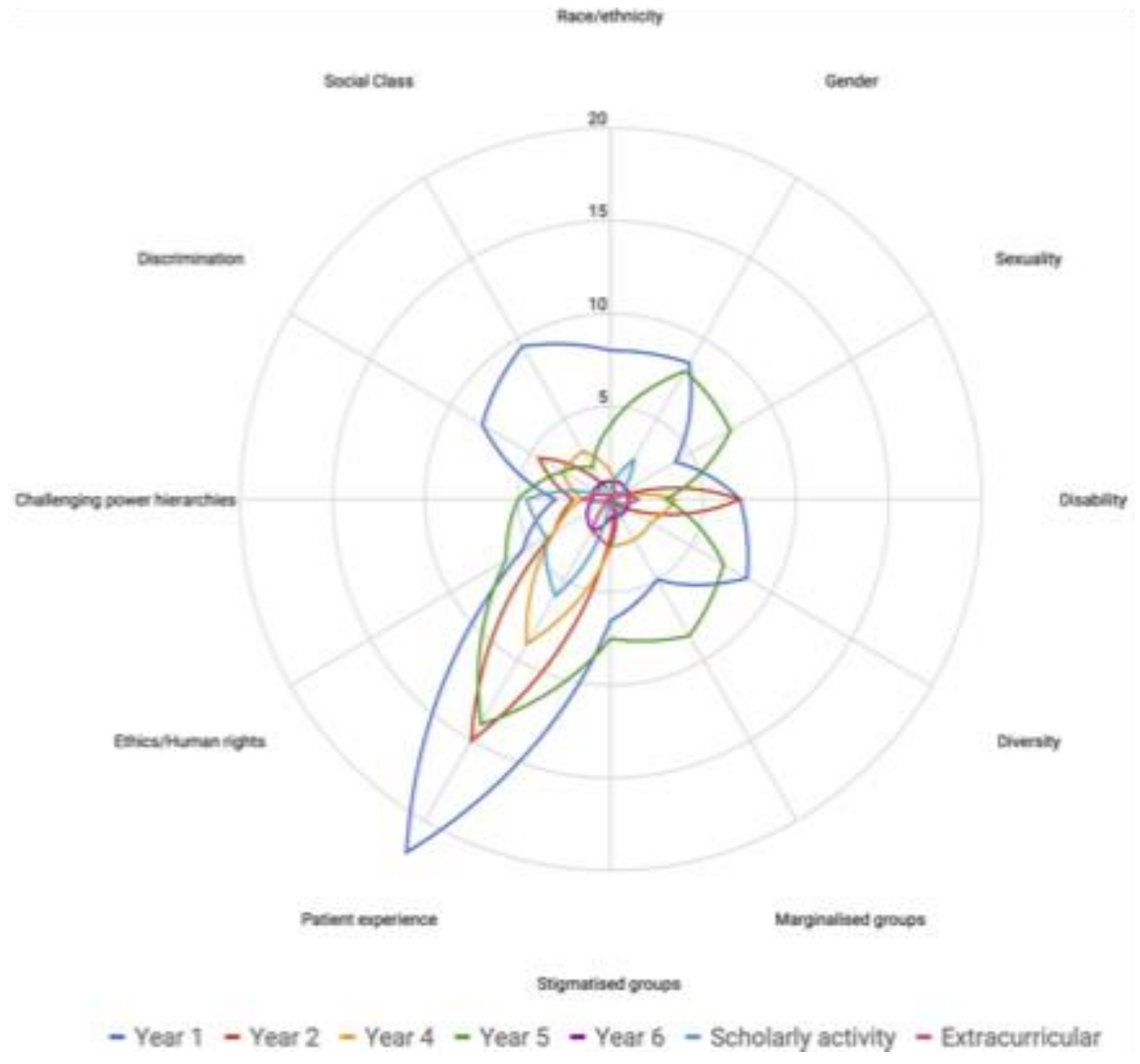

Figure 1. Wind rose diagram showing the curriculum mapping of the UCLMS curriculum.

The results of the mapping are shown in Figure 1. In this wind rose diagram, each coloured line represents an individual year of study; each axis of the circle represents a different theme. The distance of each spoke from the centre is proportionate to the level of coverage. 4

Each topic was covered at least once, with coverage often aligning with the core taught content of that year. For example, the higher coverage of gender and sexuality in Year 5 correlates

with the placements in obstetrics and gynaecology for that year. Years 4-6 appear to have fewer sessions, but clinical teaching can integrate diversity-related teaching with clinical core content, which are not formally included in the CPP curriculum. Although not every year covered all themes, every year had a marked focus on teaching students to appreciate the patient experience. 
The medical curriculum comprises the intended, 'hidden' and received curriculum. Whereas the intended curriculum includes course content and formal assessments, exposure to workplace cultural norms and system structures creates the 'hidden' curriculum. 5 The 'received' curriculum refers to the student experience. 6 Mapping exercises and checklists can shed light on the intended curriculum, but poorly reflect the gap between the intended and the taught and received curricula, as they tend to focus on the educators' perspective of planned teaching sessions, without always following up with their impact on students.

To open up conversations about this gap, in 2017 we held an engagement event, open to students, staff and the public, called 'Practically Creating an Inclusive Curriculum', where we shared our curriculum mapping. Medical students and educators shared insights into medical teaching at UCLMS, based on both personal experiences and surveys of the student population.

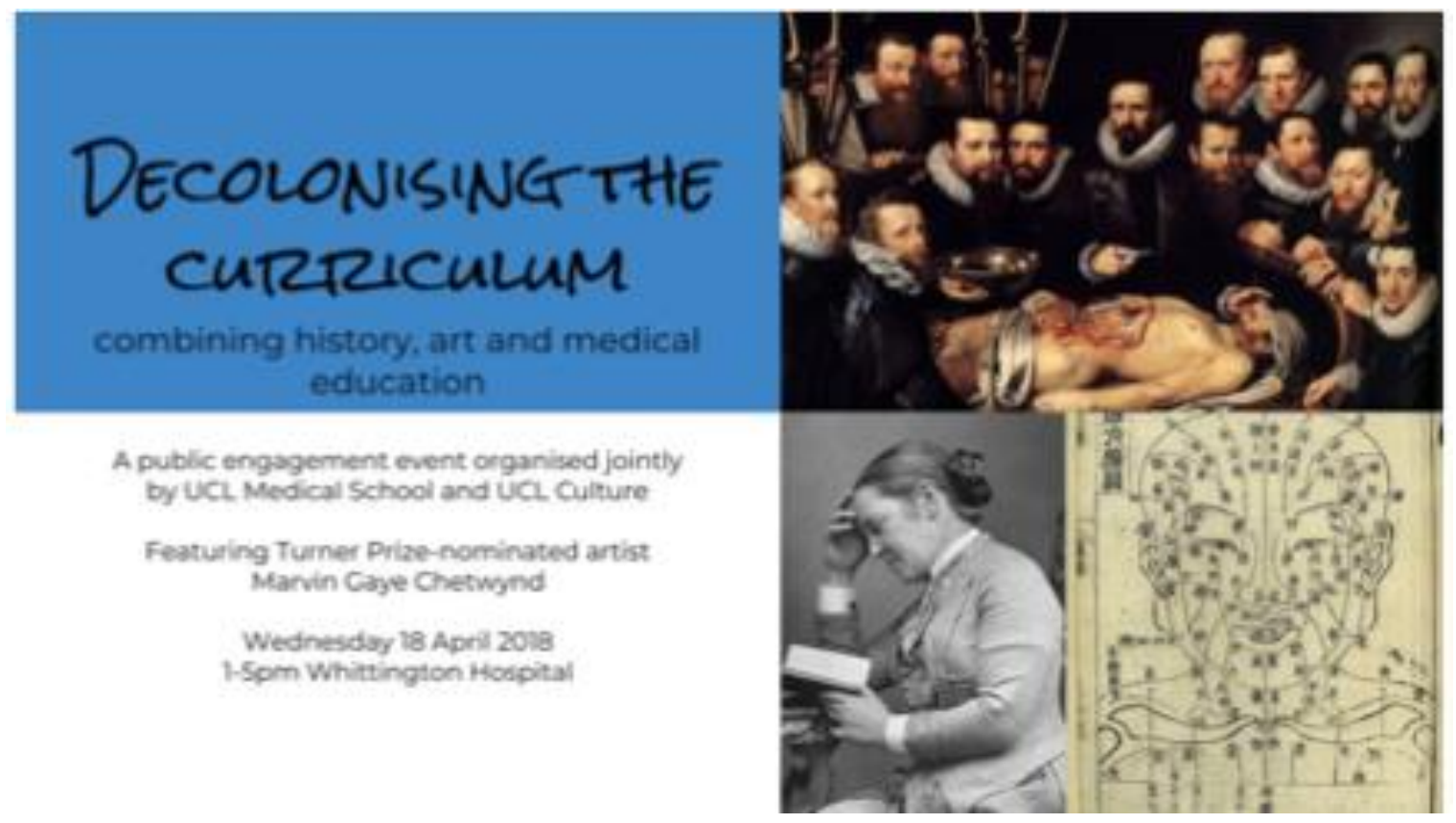

Figure 2. Publicity poster for Decolonising the Medical Curriculum, showing a montage of medical education: as seen by Europeans in the 1600s, with van Mierevelt's 'The Anatomy Lesson of Dr. Willem van der Meer'; with the gradual diversification of the medical profession, represented by Elizabeth Garrett Anderson; and with non-Western ideas of healing, demonstrated by the acupuncture pressure-points chart.

Unlike curriculum mapping, these conversations mostly captured the received curriculum, and helped to reveal gaps between the intended and the experienced curricula. One such gap was that between the planned teaching on racial diversity and the student feedback of insufficient teaching on how clinical signs varied with race and ethnicity. We have begun to address this by procur-ing skin cancer 
'stickers' to illustrate how cancer may appear on darker skins, as well as teaching about normal ranges for laboratory results that can vary by ethnic groups, e.g. renal function in Afro-Caribbean populations.

Some event participants questioned why we had not explored 'decolonisation' of the medical curriculum, that is, re-shaping teaching materials to embrace traditionally overlooked knowledge sources, especially where it concerned racially and culturally diverse patient populations. 7 In response, we held a follow-up public engagement event entitled 'Decolonising the Medical Curriculum' (DtMC).

It was encouraging that the insights raised at both events paralleled the findings from the mapping exercise. For example, a student project presented at DtMC found that students were afraid to raise concerns about the discrimination that they faced on placement, which was congruent with the lower coverage of 'challenging power hierarchies', as shown in

Curriculum 'health checks' can reveal students' exposure to diversity-related teaching and establish a baseline for future curriculum improvements. To avoid tokenistic 'tweaks', we believe that broad curriculum evaluations such as 'health checks' should come alongside student, staff and public engagement to allow us to better understand curriculum omissions and to celebrate excellence, and thus contributing to training more compassionate and culturally competent doctors. Inclusivity in medical education should not merely be a gesture towards so-called 'political correctness'; instead, it is a journey that will require curiosity, courage and humility as we navigate the depths of ingrained power imbalances in health care.

\section{REFERENCES}

1. General Medical Council. Outcomes for Graduates. 2018. Available at https://www.gmc-uk.org//media/ documents/dc11326-outcomes-for-graduates-2018_pdf-75040796.pdf. Accessed on 24 April 2019.

2. University College London. New checklist helps staff rate inclusivity of their programmes. 2018. Available at https://www.ucl.ac.uk/ teaching-learning/news/2018/may/ new-checklist-helps-staff-rateinclusivity-their-programmes. Accessed on 24 April 2019.

3. UCL Clinical and Professional Practice. Clinical and Professional Practice Student Guide. 2018. Available at https://www.ucl. ac.uk/medical-school/sites/medic al-school/files/cpp-studyguide.pdf. Accessed on 24 April 2019.

4. Albo $Y$, Lanir J, Bak $P$, Rafaeli S. Off the radar: comparative evaluation of radial visualization solutions for composite indicators. IEEE Trans Vis Comput Graph 2016;22(1):569-578.

5. Lempp H, Seale $\mathrm{C}$. The hidden cur- riculum in undergraduate medical education: quali- tative study of medical students' perceptions of teaching. BMJ 2004;329(7469):770-773.

6. Wachtler $\mathrm{C}$, Troein M. A hidden curriculum: mapping cultural com- petency in a medical programme. Med Educ 2003;37(10):861-868.

7. Pentecost $M$, Gerber $B$, Wainwright $M$, Cousins $T$. Critical orientations for humanising health sciences education in South Africa. Med Humanit 2018;44(4):221-229. 